\title{
A comparative study of four approaches to assess phenology of Populus in a short-rotation coppice culture
}

\author{
Stefan PP Vanbeveren ${ }^{(1)}$, \\ Jasper Bloemen ${ }^{(1-2)}$, \\ Manuela Balzarolo (i), \\ Laura S Broeckx ${ }^{(1)}$, \\ Isabele Sarzi-Falchi ${ }^{(1-3)}$, \\ Melanie S Verlinden ${ }^{(1)}$, \\ Reinhart Ceulemans ${ }^{(1)}$
}

\begin{abstract}
We compared four approaches to assess phenology in a short-rotation coppice culture with 12 poplar (Populus) genotypes. The four approaches quantified phenology at different spatial scales and with different temporal resolutions: (i) visual observations of bud phenology; (ii) measurements of leaf area index; (iii) webcam images; and (iv) satellite images. For validation purposes we applied the four approaches during two years: the year preceding a coppice event and the year following the coppice event. The delayed spring greenup and the faster canopy development in the year after coppicing (as compared to the year before coppicing) were similarly quantified by the four approaches. The four approaches detected very similar seasonal changes in phenology, although they had different spatial scales and a different temporal resolution. The onset of autumn senescence after coppicing remained the same as in the year before coppicing according to the bud set observations, but it started earlier according to the webcam images, and later according to the MODIS images. In comparison to the year before coppicing, the growing season - in terms of leaf area duration - was shorter in the year after coppicing, while the leaf area index was higher.
\end{abstract}

Keywords: ExG Index, Leaf Area Index, MODIS, NDVI, WRDVI, POPFULL
Partanen et al. 1998, Pauley \& Perry 1954), and reproduction (Brearley et al. 2007, Koenig et al. 2012). Within the Populus genus there is a large genotypic variation in, and a strong genetic control of the timing of bud burst (Frewen et al. 2000, Pellis et al. 2004a) and of bud set (Rohde et al. 2011a, Rohde et al. 2011b). In (intensively) managed forest ecosystems (e.g., shortrotation coppices - SRCs) additional management factors also alter the pattern of annual phenological events. SRCs are often established with Populus species and coppicing is the most influential, recurrent management factor, whereby all aboveground biomass is harvested (Hansen et al. 1979). However, data on the impact of coppicing on phenology are largely missing (Pellis et al. 2004b). they are crucial for tree growth (Seiwa 1998), survival (Junttila \& Hanninen 2012, an integrative measure of plant responses to environmental changes (Richardson et al. 2013, Schwartz 2013). The timings of bud burst and bud set are adapted to the local climate (Hamann 2004, Vitasse et al. 2014);

$\square$ (1) University of Antwerp, Department of Biology, Research Center of Excellence on Plant and Vegetation Ecology, Universiteitsplein 1, B-2610 Wilrijk (Belgium); (2) University of Innsbruck, Institute of Ecology, Research group on Ecophysiology and Ecosystem Processes, SternwartestraBe 15, 6020 Innsbruck (Austria); (3) Instituto Florestal, Seção de Silvicultura, Rua do Horto 931, CEP 02377-000, São Paulo (Brazil)

@ Stefan PP Vanbeveren (stefan.vanbeveren@uantwerp.be)

Received: Aug 10, 2015 - Accepted: Feb 15, 2016

Citation: Vanbeveren SPP, Bloemen J, Balzarolo M, Broeckx LS, Sarzi-Falchi I, Verlinden MS, Ceulemans R (2016). A comparative study of four approaches to assess phenology of Populus in a short-rotation coppice culture. iForest 9: 682-689. - doi: 10.3832/ifor1800-009 [online 2016-05-12]

Communicated by: Silvano Fares
Plant phenology is quantified via different approaches at different spatial scales and with different temporal resolutions. Visual field observations of single species are the oldest and the most direct approach (Root et al. 2003, Sparks \& Carey 1995). Monitoring the leaf area index ( $\mathrm{LAl}$ ) of experimental areas of limited size is also used to quantify phenology (Al Afas et al. 2005, Dunlap et al. 1995, Richardson et al. 2009b). More recently, flux measurements (Migliavacca et al. 2011, Sonnentag et al. 2012) and digital repeated photography (Richardson et al. 2007, 2009a, Hufkens et al. 2012, Keenan et al. 2014, Klosterman et al. 2014) have automated phenological observations and increased the spatial scale of observation. The use of satellite images represents the most recent advanced approach in phenological studies, extending the spatial (Jeganathan et al. 2014) and temporal (Myneni et al. 1997, Everill et al. 2014, Wu et al. 2014) scales to continents and decades, respectively. Only a few studies have compared different methods to monitor the phenology of forest ecosystems (Fisher \& Mustard 2007, Klosterman et al. 2014), though this is of particular interest for the validation of satellite images (Soudani et al. 2012). At present we lack such methodological comparisons for intensively managed ecosystems as SRCs. The specific nature of SRCs at the interface between agriculture and forestry also allows testing of new indices used for monitoring phenology. The wide dynamic range vegetation index (WDRVI) for example, which is a satellite based MODIS vegeta- 


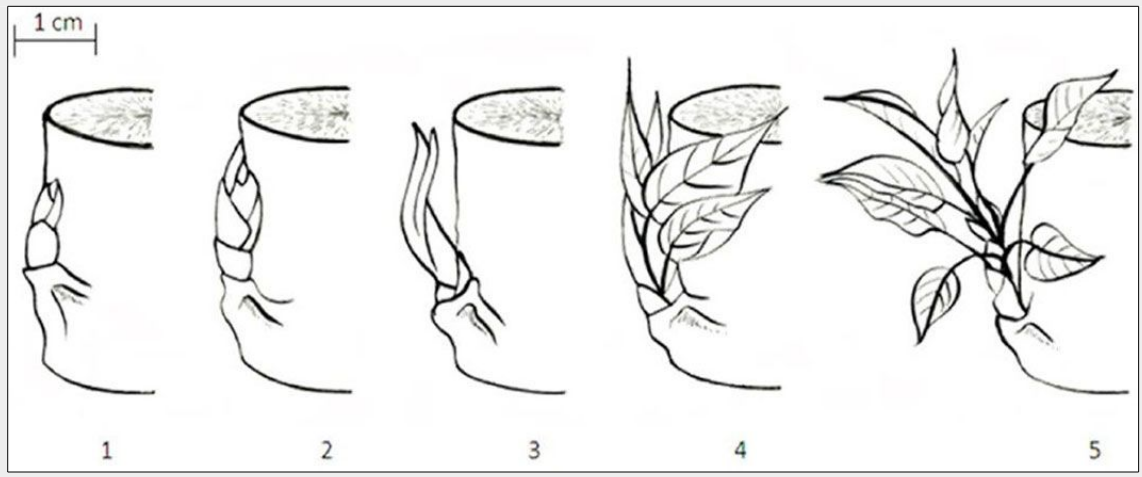

Fig. 1 - Schematic presentation of the five discrete classes used for scoring bud burst in poplar. (1) Dormant bud completely encapsulated by the bud scales, completely dry outlook and brown color; (2) buds sprouting, with a tip of the small leaves emerging out of the scales, leaves cannot be observed individually; (3) buds completely opened with leaves still clustered together, scales still present, leaves individually visible but folded on it; (4): leaves diverging with their blades still rolled up, scales may be present or absent, folded leaves starting to open, leaf venation visible; (5): leaves completely unfolded (but smaller in size than mature ones), lengthening of the axis of the shoot evident, scales absent, development of leaves from the elongation of the lateral branch (Pellis et al. 2004b, Turok et al. 1996).

tion index, has been applied for agricultural purposes, but has not yet been thoroughly tested for forest plantations (Jonsson et al. 2010).

In this study we compared different methods to monitor phenology. We applied four approaches at an operational SRC over two distinct years, i.e., the year before and the year after coppicing. The four approaches were: (i) visual observations of bud phenology; (ii) measurements of LAl; (iii) webcam images; and (iv) satellite images. The primary objective of this study was to compare the four approaches to the phenological changes and among each other.

\section{Materials and Methods}

\section{Site description}

All observations were made at the operational SRC plantation "POPFULL" in Lo-

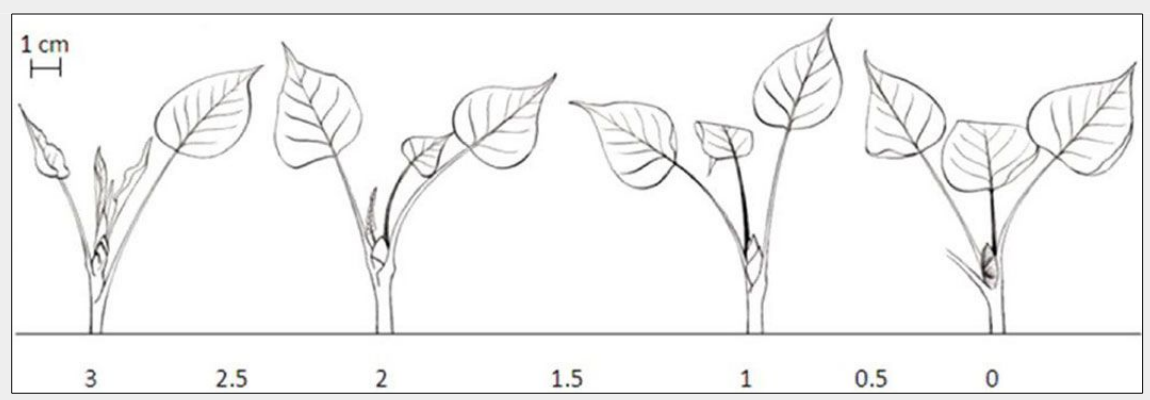

Fig. 2 - Schematic presentation of the seven discrete classes used for scoring bud set in poplar. (0): Apical bud red-brown; (0.5): apical bud fully closed, color between green and red, stipules of the two last leaves still green; (1): apical bud not fully closed, bud scales predominantly green, no more rolled-up leaves; (1.5): transition from shoot to bud structure, color of second last leaf is comparable to older leaves, last leaf partially rolled; (2): shoot/internode growth reduced, second last leaf fully stretched, last leaf bright green; (2.5): last leaves still rolled-up, last leaves at equal height, internodes become shorter; (3): apical shoot fully growing, > 2 rolled-up young leaves (Turok et al. 1996, Pellis et al. 2004b). sisted of coppiced stools with up to 46 shoots per stool (Verlinden et al. 2015).

A meteorological mast in the plantation continuously monitored all meteorological variables from May 2010 onward. Photosynthetically active radiation (PAR, 400-700 $\mathrm{nm}$ ) was continuously recorded above the canopy using a quantum sensor (LI-190, LiCor Inc., USA - Zona et al. 2013). Volumetric soil water content was measured horizontally at specific depths of $1 \mathrm{~m}, 60 \mathrm{~cm}, 40$ $\mathrm{cm}, 30 \mathrm{~cm}$, and $20 \mathrm{~cm}$ below the surface, using soil moisture probes (TDR model CS616, Campbell Scientific, USA). Air temperature was recorded using a Vaisala probe (model HMP45C, Vaisala, Finland) mounted on a telescopic mast next to the meteorological mast. For a complete description of all instruments and sensors on the meteorological mast, the reader is referred to an earlier publication (Zona et al. 2013).

\section{Assessments of phenology}

\section{Visual observations of bud phenology}

Bud burst and bud set were visually and intensively scored per genotype during the spring and the autumn, before (year 2011) and after (year 2012) coppicing. We applied the bud burst scoring system (with five discrete classes) previously developed and validated for poplar (Pellis et al. 2004b, Turok et al. 1996 - Fig. 1). During the spring of 2011 (late February - mid-May) the gradual process of bud burst and leaf development was quantified each week by assigning scores to eight plots of four trees per genotype. Bud burst scores were averaged per DOY. In the spring of 2012 (early April mid-May) one of the five scores was as signed to each monogenotypic block as a whole on a weekly basis. In 2011 observations were made on the buds of the upper part of the main current-year axis, while in 2012 observations were made on the buds of the stumps.

Autumn phenology, i.e., the end of tree height growth and of leaf production, was assessed using a bud set scoring system (with seven discrete classes) established and validated for poplar (Rohde et al. 2011b - Fig. 2). Analogously to bud burst, scores were assigned each week to eight plots of four trees of each genotype in the autumn of 2011 (late August - early October). In the autumn of 2012 (late August - mid-October) two plots of four trees were assigned to one of the seven classes on a weekly basis and these values were averaged per DOY. As for the bud burst scoring, we scored the apical bud on the main currentyear axis in 2011 and the apical buds on all resprouting axes in 2012.

\section{Leaf area index measurements}

Leaf area index ( $\mathrm{LAl}$ ) was indirectly measured using the $\mathrm{LI}-2200$ plant canopy analyser (LiCor Inc., USA) with a $45^{\circ}$ view cap. The measurements were taken on a regular basis ( \pm every two weeks) during the 
year before and the year after coppicing in 96 predetermined plots equally spread over the different genotypes and the two former land use types: 12 genotypes $\times 2$ former land uses $\times 4$ replicates. Per plot, two diagonal transects were made between the planted rows (Fig. 3). Per transect, six sample measurements were taken: three parallel to the rows and three perpendicular to the rows (Broeckx et al. 2015 - Fig. 3). Using the software FV2200 (version 1.0.0, LiCor Inc., USA), sample measurements were combined to generate one LAI value per plot, which was averaged to one value for the entire plantation. In the year after coppicing, the onset of spring greenup could not be monitored because leaves were too close to the ground, hence inhibiting correct below-canopy light measurements.

\section{Webcam image acquisition}

Webcam images were obtained using a standard commercially available webcam (AXIS P1344, Axis Communications AB, Sweden) mounted in a weatherproof enclosure; full technical specifications are available online (Axis Communications 2012). The webcam was installed on the telescopic mast at a height of $4 \mathrm{~m}$, facing west-southwest and set at an angle of $20^{\circ}$ below horizontal (Hufkens et al. 2012). The webcam remained in the same position and orientation during the two years of this study. Images were stored as minimally compressed JPEG files $(1024 \times 768$ pixels). Analyses were performed on a rectangular region of interest (ROI - Fig. 4). Images were collected every day at 10:00 AM (solar time). Images with raindrops or direct sunlight on the lens were discarded, keeping 323 (out of 365) images for 2011 and 331 (out of 366) images for 2012.

The phenocam Matlab script (available at http://phenocam.sr.unh.edu/webcam/) was used to analyse the digital image files ( $\mathrm{Ri}$ chardson et al. 2007). Webcam color channel information (i.e., digital numbers - DNs) was extracted from the JPEG files and averaged across the ROI for red, green and blue (RGB) color channel and expressed in percentage. The overall brightness of the ROI was calculated as the sum of the DN of the three color channels (eqn. 1):

Total $R G B D N=\operatorname{red} D N+$ green $D N+$ blue $D N$

The relative channel brightness of each channel (i.e., channel \%) was calculated by dividing the channel $D N$ by the total RGB DN (Richardson et al. 2007 - eqn. 2):

$$
\text { Channel }=\frac{\text { Channel } D N}{\text { Total RGB DN }}
$$

For the ROI of each image the excess green index $(\mathrm{ExG})$ was calculated as the difference in divergence of both the red and the blue channels from the green channel \% as described by Richardson et al. (2007) - eqn. 3:

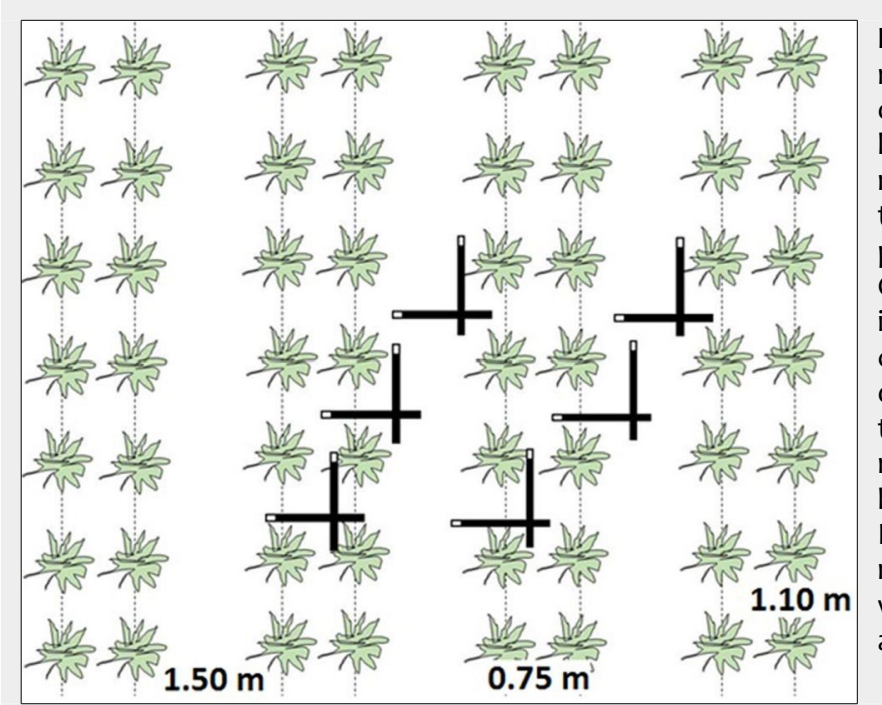

Fig. 3 - Schematic representation of one plot used for leaf area index (LAI) measurements in the double-row planting design. Green silhouettes indicate individual coppiced stumps; dotted lines indicate the direction of the row. Thick black bars represent the LI-2200 LAl instrument, with the white tip as the actual light sensor.

$$
E x G=2 \cdot \operatorname{green} D N-(\operatorname{red} D N+\text { blue } D N)
$$

This index is commonly used to discriminate leaf cover from the soil background in forest canopy phenology studies (Hufkens et al. 2012).

Using the method described by Zhang et al. (2003) and applied by Hufkens et al. (2012), the DOY phenophase transition dates were estimated as follows: (i) $\mathrm{ExG}_{\text {in }}$, the date of spring onset; (ii) $\mathrm{ExG}_{\max }$, when maximum green leaf area was reached; (iii) $\mathrm{ExG}_{\mathrm{de}}$, the date when photosynthetic activity and green leaf area began to rapidly decline; (iv) $\mathrm{ExG}_{\min }$, the date at which physiological activity became near to zero. To determine the transition dates, we used the ExG data spanning the period between DOY 50-150 (in 2011) and DOY 100-200 (in
2012) for the spring and between DOY $250-$ 366 for the autumn. A single sigmoidal curve per season was fitted to the data in $\mathrm{R}$ ( $R$ core team 2013), from which phenophase transition dates were extracted (Zhang et al. 2003 - eqn. 4 to eqn. 7):

$$
\begin{array}{ll}
\text { Spring 2011: } & Y=\frac{65.28}{1+e^{\frac{91.13-x}{10.75}}} \\
\text { Autumn 2011: } & Y=\frac{50.50}{1+e^{\frac{310.12-x}{-13.67}}} \\
\text { Spring 2012: } & Y=\frac{70.39}{1+e^{\frac{145.51-x}{6.90}}} \\
\text { Autumn 2012: } & Y=\frac{45.27}{1+e^{\frac{323.62-x}{-3.65}}}
\end{array}
$$

Greenup (defined as $\mathrm{ExG}_{\max }-\mathrm{ExG}_{\text {in }}$ ) and

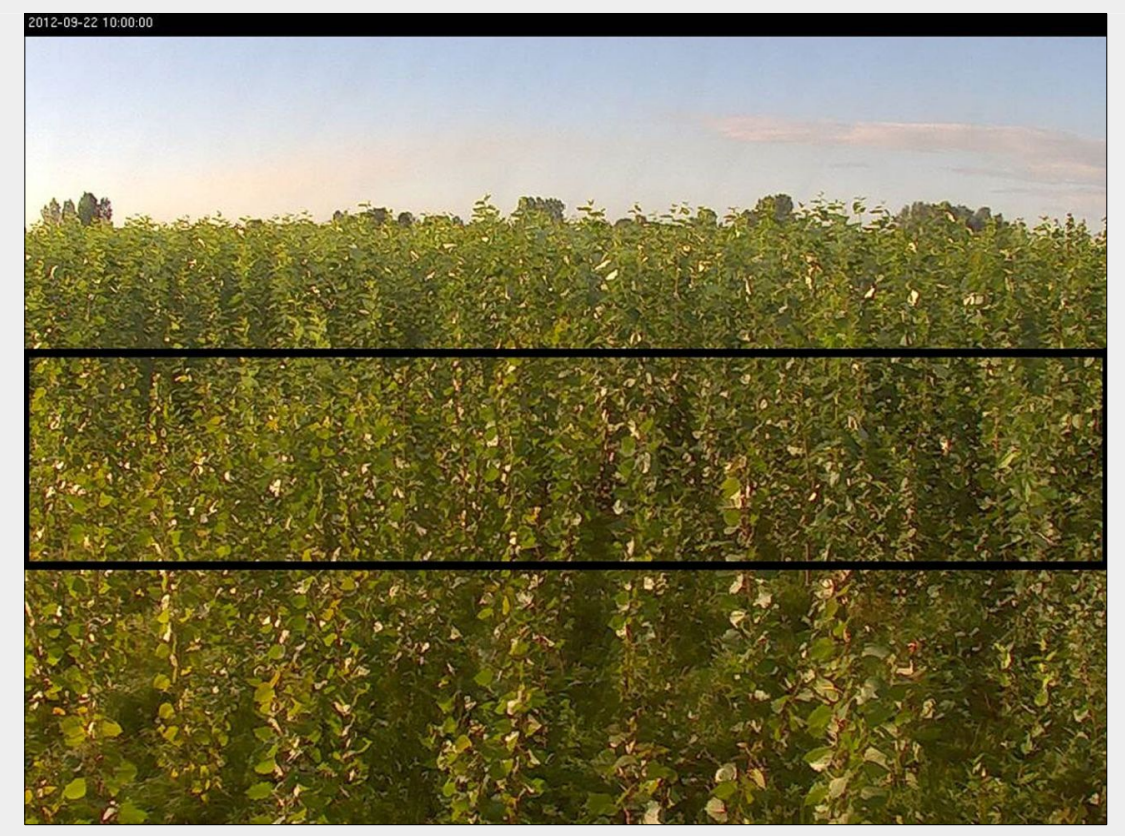

Fig. 4 - Example of webcam image (date: Sep 22, 2012) in the year after coppicing of the poplar short-rotation coppice (SRC). The region of interest (ROI) used for the analyses is indicated by the black rectangle. 
senescence (defined as $E x G_{\min }$ - $E x G_{d e}$ ) duration were calculated to provide information about leaf development in spring and leaf shedding in autumn (Hufkens et al. 2012). Leaf area duration (LAD, calculated as $\left.E x G_{\min }-E_{x G_{\text {in }}}\right)$ was determined as an indicator of the length of the growing season.

\section{Satellite image processing (MODIS)}

MODIS vegetation indices (NDVI and WDRVI) were calculated from MODogGQ "MODIS/Terra Surface Reflectance Daily L2G Global 250m". Each MODogGQ pixel contained daily red and near-infrared reflectance data at a $250 \mathrm{~m}$ resolution as well as additional information on band quality, orbit and coverage, and number of observations. MODIS data were ordered and downloaded via the MODIS Adaptive Processing System (MODAPS) Services website. From this dataset, the following vegetation indices were calculated: (i) the normalized difference vegetation index (NDVI, Rouse et al. 1974 - eqn. 8):

$$
N D V I=\frac{\rho_{N I R}-\rho_{\text {red }}}{\rho_{\text {NIR }}+\rho_{\text {red }}}
$$

and (ii) the wide dynamic range vegetation index (WDRVI, Gitelson 2004 - eqn. 9):

$$
W D R V I=\frac{\alpha \cdot \rho_{\text {NIR }}-\rho_{\text {red }}}{\alpha \cdot \rho_{\text {NIR }}+\rho_{\text {red }}}
$$

where $\rho_{\text {red }}$ and $\rho_{\text {NIR }}$ are reflectance values for respectively MODIS band 1 (620-670 $\mathrm{nm})$ and band $2(841-871 \mathrm{~nm})$, and $\alpha$ is a weighing factor (i.e., 0.2 for row crops Viña et al. 2004). MODIS data were resampled by using the Nearest Neighbour resampling algorithm and the selected projection was Geographic (i.e., GEO: WGS 84 lat/lon). From resampled and georeferenced MODogGQ time-series for 2011 and 2012 we extracted one pixel $(250 \times 250 \mathrm{~m})$ corresponding to the site coordinates for each day.

For the MODIS data quality check we used the available information retrieved in the MODogGQ for band 1 (NIR) and band 2 (red). MODogA1 pixel values represent the optimal reflectance values within a time window of 8-days. Only the pixels with the highest quality (e.g., clear sky conditions without snow) and flagged as "good" were selected and retained for further use. The MODIS data processing was compiled using the MATLAB software (MATLAB $v$. 2012a, MathWorks, Natick, MA, USA).

The method described by Zhang et al. (2003) was used to derive the phenological transition dates from MODIS vegetation indices time series. The NDVI is the most widely used indicator related to vegetation greenness (Bohovic \& Dobrovolny 2013), while the WDRVI was recently developed as an expansion of the NDVI, to reduce the latter's sensitivity to saturation effects (Viña \& Gitelson 2005).

\section{Results}

The growing seasons of 2011 and 2012 were very comparable in terms of climate conditions. The main meteorological variables - PAR (Fig. 5a) and air temperature (Fig. 5b) - were confined within compara-

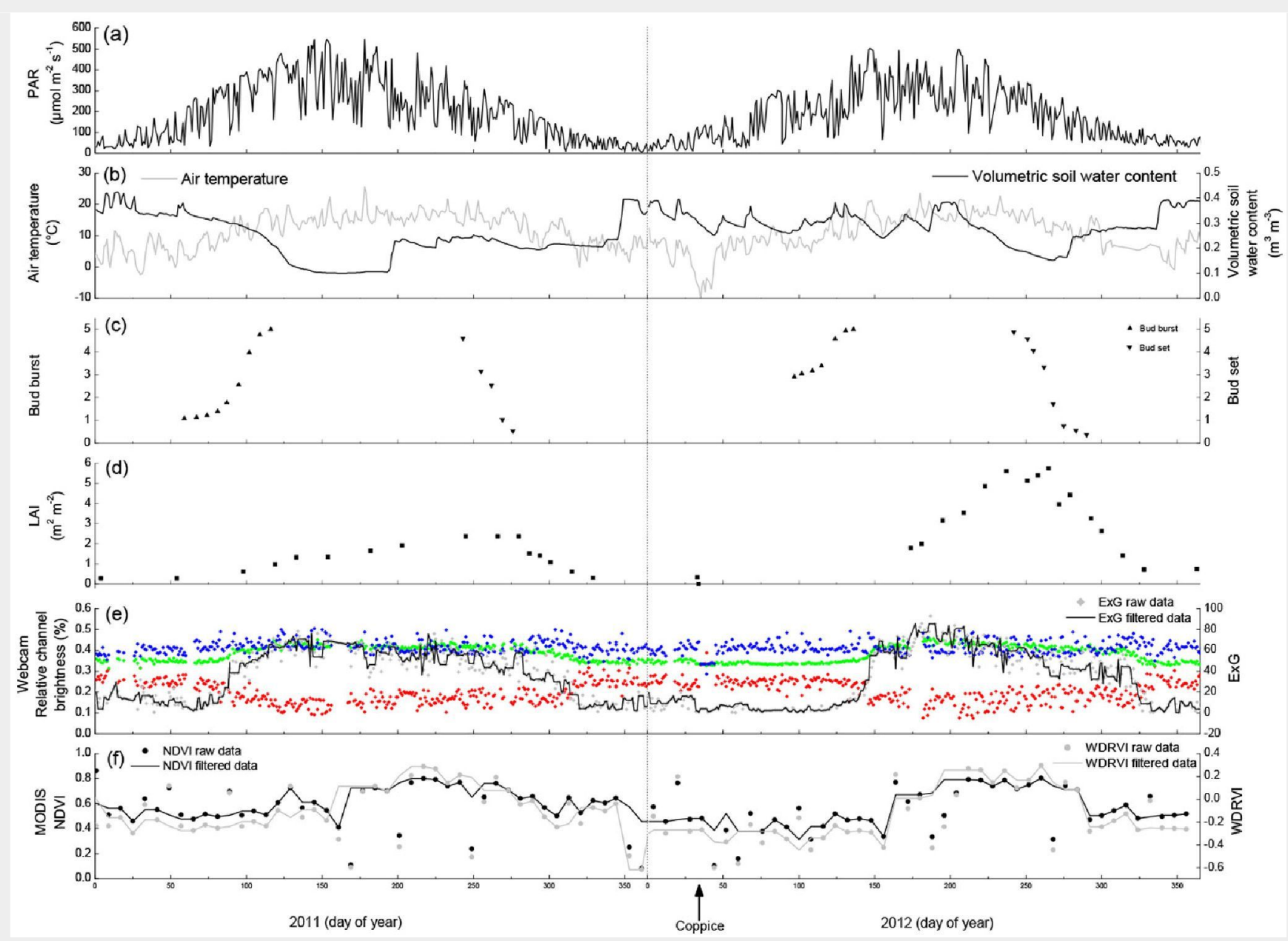

Fig. 5 - Environmental variables and phenological indicators measured at the short-rotation coppice plantation in the years 2011 (before coppicing) and 2012 (after coppicing). The coppice was carried out on 2-3 February 2012 (DOY 34-35) as indicated by the

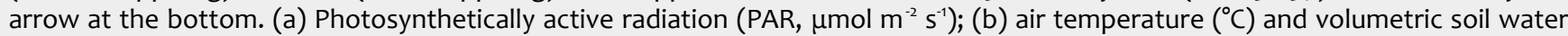
content $\left(\mathrm{m}^{3} \mathrm{~m}^{-3}\right)$; (c) bud burst and bud set phenology expressed on a scale of discrete classes; (d) leaf area index (LAI, $\left.\mathrm{m}^{2} \mathrm{~m}^{-2}\right) ;(\mathrm{e})$ relative red, blue and green channel brightness (\%, respectively in red, blue and green squares), and the excess green index (ExG, raw data and filtered data are shown) extracted from the webcam images; ( $f$ ) normalized difference vegetation index (NDVI) and wide dynamic range vegetation index (WDRVI) from the MODIS satellite image. 
ble limits and showed similar patterns during both growing seasons. The volumetric soil water content (Fig. 5b) was in the same range for both growing seasons, although soils dried out more and earlier in the summer of 2011 as compared to 2012. This might be resulting from the larger amount of transpired water in 2011 as more above-ground biomass was present. The phenology assessed at bud and at plant level showed similar seasonal trends in 2011 and 2012. Bud burst (Fig. 5C) occurred at DOY 50-125 in the year before coppicing and lagged till DOY 75-150 in the year after coppicing. This lag time was the result of the coppicing in February 2012, as new buds had to be formed from meristematic cells on the coppiced stumps. Bud set, however, occurred in both years at DOY 225-275. In the year before coppicing the LAI (Fig. 5d) started to increase around the same time as the bud burst and the maximum seasonal LAI (2.4) was reached by the time bud set was completed. The direct effect of the coppice was evidenced by the LAI data, because these dropped from 0.33 (also known as the branch area index) to zero on DOY 33-34, the days on which the coppice was executed. The maximum seasonal LAI (5.7) was again reached by the time bud set was completed in the year after coppicing.

The relative channel brightness derived from the webcam images (Fig. 5e) showed several clear phenological patterns. Taking into account the day-to-day variations, the red \% decreased between DOY 75-125 (before coppicing) and DOY 100-150 (after coppicing); the autumn red signal was visible around DOY 325 in both years. Apart from minor day-to-day variations, the blue $\%$ remained fairly constant over both years. The green \% had the least day-to-day variations, and showed a trend opposing the one observed for the red \%. The green \% dynamics were more expressed by the ExG (Fig. 5e). Spring greenup in the year before coppicing occurred in the last half of the period as quantified by the bud burst and LAI, while the leaf colours gradually changed between DOY 225 and 350 (Fig. 5e). Spring greenup took off after bud burst was completed in the year after coppicing, while the leaf colours changed as gradually as in the year before coppicing (Fig. 5e). The effect of coppicing is both directly and indirectly visible from our data. It is directly visible because the red, green and blue \% converged to 33\% (typical for snow cover on a bare soil) at the moment of the coppicing. In an indirect way, the coppice postponed the onset of spring greenup, thereby shortening the LAD by 63 days (as compared to the year before coppicing) and because the maximum seasonal ExG increased from 78 before coppicing to 93 after coppicing (Tab. 1). The maximum seasonal ExG values were reached earlier in the season in both years as compared to the maximum seasonal LAI values. The NDVI and the WDRVI showed very

Tab. 1 - Dates of different phenological events derived from webcam (excess green index, ExG) and satellite (NDVI and WDRVI) images in the years before coppicing (2011) and after coppicing (2012). All dates are expressed in terms of day of year (DOY). ( $\left(\mathrm{XG}_{\mathrm{in}}\right)$ : onset of spring greenup; $\left(\mathrm{ExG}_{\max }\right)$ : start of maximum greenness, $\left(E x G_{\text {de }}\right)$ : start of senescence; $\left(E x G_{\text {min }}\right)$ : start of minimum greenness; (NDVI): normalized difference vegetation index; (WDRVI): wide dynamic range vegetation index.

\begin{tabular}{lcccccc}
\hline \multirow{2}{*}{ Parameter } & \multicolumn{2}{c}{ Webcam } & \multicolumn{2}{c}{ NDVI } & \multicolumn{2}{c}{ WDRVI } \\
\cline { 2 - 7 } & $\mathbf{2 0 1 1}$ & $\mathbf{2 0 1 2}$ & $\mathbf{2 0 1 1}$ & $\mathbf{2 0 1 2}$ & $\mathbf{2 0 1 1}$ & $\mathbf{2 0 1 2}$ \\
\hline ExG $_{\text {in }}$ & 65 & 121 & 64 & 104 & 80 & 148 \\
ExG $_{\max }$ & 131 & 178 & 184 & 200 & 200 & 200 \\
ExG $_{\text {de }}$ & 221 & 200 & 208 & 232 & 224 & 240 \\
ExG $_{\min }$ & 356 & 349 & 352 & 336 & 360 & 304 \\
\hline
\end{tabular}

comparable seasonal patterns in both years, although the growing season was more evident by the WDRVI in comparison to the NDVI (Fig. 5f). The NDVI confined the growing seasons within the same limits as shown by the webcam in the year before coppicing, while the WDRVI showed a lag phase of $\approx 20$ days (Tab. 1 ). In the year after coppicing the webcam results reached their peak values $\approx 15$ days later than the NDVI. The WDRVI quantified the growing season as starting later ( $\approx 25$ days) and being shorter ( $\approx 70$ days) than the growing season as quantified by the webcam. Both the NDVI and the WDRVI showed that the growing season started later (resp. 40 and 68 days) and ended earlier (resp. 16 and 64 days) in the year after coppicing as compared to the year before coppicing. Both MODIS vegetation indices were not accurate enough to identify the coppicing operation. The NDVI was more sensitive to small changes in phenology and hence responded more quickly to bud burst as compared to the WDRVI. On the other hand, bud set fell in the middle of the senescence period as estimated by both MODIS vegetation indices. The doubling of the maximum seasonal LAI value from the year before coppicing to the year after coppicing was neither translated in a doubling of the NDVI nor of the WDRVI; the NDVI and the WDRVI only slightly increased. The WDRVI was lower than the $N D V I$ at $L A I<2$, while the trend was the reverse at $\mathrm{LAI}>2$.

During senescence, the four approaches (visual observations of bud phenology, measurements of leaf area index, webcam images and satellite images) were triggered in a different way and thus also at a different time. The overall greenness obtained from both webcam and MODIS images slightly declined when older leaves got shaded by the younger leaves, because the percentage of sunlit leaves decreased relatively to the total amount of leaves. Over the entire growing season the number of young leaves relative to the total number of leaves declined, thereby causing a gradual decline in greenness. This was mainly visible in the ExG (Fig. 5c), as MODIS images (Fig. 5d) also incorporated understory weed species in the plantation. After the maximum seasonal LAl was reached, buds were set, but this bud set was not recognized in the webcam- and satellitebased phenological assessments.

\section{Discussion}

The four approaches (visual observations of bud phenology, measurements of leaf area index, webcam images and satellite images) to assess phenology clearly showed the seasonal patterns and yielded similar results, despite the methodological differences. For example, LAI values depend on light attenuation through the canopy, while the ExG, NDVI and WDRVI indices depend on canopy greenness. The four different approaches to assess phenology produced, however, different interpretations of phenology. During greenup all approaches were triggered at the same time, but in a different way: leaf buds opened, thereby unfolding leaves, which triggered the LAl by intercepting light; this also triggered the ExG because the young leaves are green. In turn this also triggered the two MODIS indices by introducing a different color palette to the observed area (Soudani et al. 2008, Richardson et al. 2009b, Hmimina et al. 2013, Klosterman et al. 2014).

The maximum seasonal LAl value in the year after coppicing was double the maximum seasonal LAI value in the year before coppicing. This could be explained by the transition from single- to multi-stem coppiced stools: up to 46 shoots per stool emerged after coppicing (Broeckx et al. 2015, Verlinden et al. 2015). This increased amplitude in LAI in the year after coppicing was weakly represented by the ExG index, while it remained unnoticed by the NDVI and WDRVI indices. In general, the ExG and the NDVI indices saturate when the LAI surpasses 2.0 (Gitelson 2004) or 2.5 (Keenan et al. 2014, Klosterman et al. 2014). Our results confirmed earlier findings on row crops (Gitelson 2004) that showed that the NDVI predicted the start $\left(\mathrm{ExG}_{\text {in }}\right)$ and the end $\left(E x G_{\min }\right)$ of the growing season (and thus, the LAD) better than the WDRVI. The WDRVI was better in representing amplitudinal differences in LAI at higher LAI values (i.e., the period of maximum greenness, from $E x G_{\max }$ until $E x G_{d e}$ ). Furthermore, the NDVI overestimates field observations (Busetto et al. 2010, Fisher \& Mustard 2007), 
but this could not be concluded from our data.

Ground validation (visual observations of bud phenology and measurements of leaf area index) of remote sensing data (webcam and satellite images) remains necessary and is still lacking for most vegetation types (Keenan et al. 2014, Zhang et al. 2003). As evident from the present study, several critical considerations should be taken into account when comparing results from approaches at different spatial and temporal scales (Richardson et al. 2007, $2009 \mathrm{~b}$ ). First, the steep rate of the spring greenup curve as observed by the webcam images might be exaggerated because of the oblique viewing angle of the webcam. This oblique viewing angle looks upon more layers of leaves as when it would face $90^{\circ}$ downwards (Keenan et al. 2014). The position and the angle of the webcam were chosen as a compromise to include as many trees in the field of view as possible and at the same time maximizing the resolution in the ROI during the growing season. Nevertheless, the field of view changed according to the cosine law: with increasing canopy height, the horizontal area visible by the webcam became smaller. Secondly, the extent of autumn senescence at the end of the growing season might be overestimated, as the ROI images integrated several different poplar genotypes, which differed in the timing of different phenological stages (Pellis et al. 2004a, Broeckx et al. 2014). Therefore the webcam images aggregated the phenological responses of the different poplar genotypes, leading to an increased overall duration of spring greenup and autumn senescence (Hufkens et al. 2012, Klosterman et al. 2014). However, the impact of coppicing on phenology was clearly visible. Thirdly, no white or grey reference panel was installed in the field of view of the webcam. The installation of a reference panel could lead to a more pronounced variability in the channel brightness due to changes in the quality and the quantity of incident solar radiation (Richardson et al. 2007, Migliavacca et al. 2011, Sonnentag et al. 2012). Nevertheless, the timing of the different phenological events was clearly visible from our webcam images. Finally, the accuracy of the MODIS vegetation indices was limited to one pixel only, with considering geolocation details. Although this may not seem representative at first, the single pixel approach has been used before (Tan et al. 2006).

\section{Conclusions}

In conclusion, the four approaches to quantify phenological events agreed rather well and clearly reflected the effect of coppicing. Considering the different spatial scales and temporal resolutions of the four approaches, they all confirmed each other. However, it is important to keep the methodological differences and the different plant attributes assessed with every approach in mind when different approaches are compared or simultaneously applied.

\section{Acknowledgements}

This research has received funding from the European Research Council under the European Commission's Seventh Framework Program (FP7/2007-2013) as ERC grant agreement $n^{\circ} 233366$ (POPFULL). Further funding was provided by the Flemish government through the Hercules Foundation as Infrastructure Contract ZWo9-06 and by the Methusalem Program. We gratefully acknowledge the technical support of Joris Cools and the logistic support of Kristof Mouton at the field site, as well as the useful suggestions by Koen Hufkens (Harvard University, USA).

\section{References}

Al Afas N, Pellis A, Niinemets U, Ceulemans R (2005). Growth and production of a short rotation coppice culture of poplar. II. Clonal and year-to-year differences in leaf and petiole characteristics and stand leaf area index. Biomass and Bioenergy 28: 536-547. - doi: 10.1016/j.biombioe.2004.11.010

Axis Communications AB (2012). AXIS P1344 Network camera user manual. Axis Communications, Sweden, pp. 58. [online] URL: http:// www.axis.com/files/manuals/um_p1344_48168 en_1208.pdf

Berhongaray G, El Kasmioui $O$, Ceulemans R (2013). Comparative analysis of harvesting machines on an operational high-density short rotation woody crop (SRWC) culture: one-process versus two-process harvest operation. Biomass and Bioenergy 58: 333-342. - doi: 10.1016/j. biombioe.2013.07.003

Bohovic R, Dobrovolny P (2013). Vegetation phenology in central Asia by means of remote sensing. In: Proceedings of the " 3 rd Annual Global Change and Resilience Conference: from impacts to responses (vol. 1)" (Stojanov R, Zalud Z, Cudlin P, Farda A, Urban O, Trnka M eds). Global Change Research Centre, Academy of Sciences of the Czech Republic, vvi Brno, Czech Republic, pp. 131-135. [online] URL: http://www.researchgate.net/profile/Roman_B ohovic2/publication/261031885

Brearley FQ, Proctor J, Suriantata Nagy L, Dalrymple G, Voysey BC (2007). Reproductive phenology over a 10-year period in a lowland evergreen rain forest of central Borneo. Journal of Ecology 95: 828-839. - doi: 10.1111/j.1365-2745. 2007.01258.x

Broeckx LS, Fichot R, Verlinden MS, Ceulemans R (2014). Seasonal variations in photosynthesis, intrinsic water-use efficiency and stable isotope composition of poplar leaves in a short-rotation plantation. Tree Physiology 34: 701-715. - doi: 10.1093/treephys/tpu057

Broeckx LS, Vanbeveren SPP, Verlinden MS, Ceulemans R (2015). First vs. second rotation of a poplar short rotation coppice: leaf area development, light interception and radiation use efficiency. iForest - Biogeosciences and Forestry 8: 565-573. - doi: 10.3832/ifor1457-008

Broeckx LS, Verlinden MS, Ceulemans R (2012). Establishment and two-year growth of a bio- energy plantation with fast-growing Populus trees in Flanders (Belgium): effects of genotype and former land use. Biomass and Bioenergy 42: 151-163. - doi: 10.1016/j.biombioe.2012. 03.005

Busetto L, Colombo R, Migliavacca M, Cremonese E, Meroni M, Galvagno M, Rossini M, Siniscalco C, Di Cella UM, Pari E (2010). Remote sensing of larch phenological cycle and analysis of relationships with climate in the Alpine region. Global Change Biology 16: 2504-2517. - doi: 10.1111/j.1365-2486.2010.02189.x

Diez JM, Ibanez I, Silander JA, Primack R, Higuchi H, Kobori H, Sen A, James TY (2014). Beyond seasonal climate: statistical estimation of phenological responses to weather. Ecological Applications 24: 1793-1802. - doi: 10.1890/13-1533.1 Dunlap JM, Heilman PE, Stettler RF (1995). Genetic variation and productivity of Populus trichocarpa and its hybrids. VIII. Leaf and crown morphology of native $P$. trichocarpa clones from four river valleys in Washington. Canadian Journal of Forest Research 25: 1710-1724. - doi: 10.1139/x95-185

Everill PH, Primack RB, Ellwood ER, Melaas EK (2014). Determining past leaf-out times of New England's deciduous forests from herbarium specimens. American Journal of Botany 101: 1293-1300. - doi: 10.3732/ajb.1400045

Fisher JI, Mustard JF (2007). Cross-scalar satellite phenology from ground, Landsat, and MODIS data. Remote Sensing of Environment 109: 261273. - doi: 10.1016/j.rse.2007.01.004

Frewen BE, Chen THH, Howe GT, Davis J, Rohde A, Boerjan W, Bradshaw HD (2000). Quantitative trait loci and candidate gene mapping of bud set and bud flush in Populus. Genetics 154: 837-845. [online] URL: http://www.genetics. org/content/154/2/837.short

Gitelson AA (2004). Wide dynamic range vegetation index for remote quantification of biophysical characteristics of vegetation. Journal of Plant Physiology 161: 165-173. - doi: 10.1078/ 0176-1617-01176

Hakkinen R, Linkosalo T, Hari P (1998). Effects of dormancy and environmental factors on timing of bud burst in Betula pendula. Tree Physiology 18: 707-712. - doi: 10.1093/treephys/18.10.707 Hamann A (2004). Flowering and fruiting phenology of a Philippine submontane rain forest: climatic factors as proximate and ultimate causes. Journal of Ecology 92: 24-31. - doi: 10.1111/j.1365-2745.2004.00845.x

Hansen EA, McNeel HA, Netzer DA, Phipps HM, Roberts PS, Strong TF, Tolsted DN, Zavitkovski $J$ (1979). Short-rotation intensive culture practices for Northern Wisconsin. In: Proceedings of the "North American Poplar Council Annual Meeting". Thompsonville (Michigan, USA) 1979. Staff of Intensive Culture Project, USA, pp. 47-63.

Hmimina G, Dufrene E, Pontailler JY, Delpierre N, Aubinet $M$, Caquet $B$, De Grandcourt A, Burban B, Flechard C, Granier A, Gross P, Heinesch B, Longdoz B, Moureaux C, Ourcival JM, Rambal S, Saint Andre L, Soudani K (2013). Evaluation of the potential of MODIS satellite data to predict vegetation phenology in different biomes: an investigation using ground-based NDVI measurements. Remote Sensing of Environment 132: 145-158. - doi: 10.1016/j.rse.2013.01.010 
Hufkens K, Friedl M, Sonnentag O, Braswell BH, Milliman T, Richardson AD (2012). Linking nearsurface and satellite remote sensing measurements of deciduous broadleaf forest phenology. Remote Sensing of Environment 117: 307321. - doi: 10.1016/j.rse.2011.10.006

Jeganathan C, Dash J, Atkinson PM (2014). Remotely sensed trends in the phenology of northern high latitude terrestrial vegetation, controlling for land cover change and vegetation type. Remote Sensing of Environment 143: 154-170. - doi: 10.1016/j.rse.2013.11.020

Jonsson AM, Eklundh L, Hellstrom M, Barring L, Jonsson $P$ (2010). Annual changes in MODIS vegetation indices of Swedish coniferous forests in relation to snow dynamics and tree phenology. Remote Sensing of Environment 114: 2719-2730. - doi: 10.1016/j.rse.2010.06.005

Junttila O, Hanninen H (2012). The minimum temperature for budburst in Betula depends on the state of dormancy. Tree Physiology 32: 337345. - doi: 10.1093/treephys/tps010

Keenan TF, Darby B, Felts E, Sonnentag O, Friedl MA, Hufkens K, O'Keefe J, Klosterman ST, Munger JW, Toomey M, Richardson AD (2014). Tracking forest phenology and seasonal physiology using digital repeat photography: a critical assessment. Ecological Applications 24: 1478-1489. - doi: 10.1890/13-0652.1

Klosterman ST, Hufkens K, Gray JM, Melaas E, Sonnentag O, Lavine I, Mitchell L, Norman R, Friedl MA, Richardson AD (2014). Evaluating remote sensing of deciduous forest phenology at multiple spatial scales using PhenoCam imagery. Biogeosciences 11: 4305-4320. - doi: 10.5194/bg-11-4305-2014

Koenig WD, Funk KA, Kraft TS, Carmen WJ, Barringer BC, Knops JMH (2012). Stabilizing selection for within-season flowering phenology confirms pollen limitation in a wind-pollinated tree. Journal of Ecology 100: 758-763. - doi: 10.1111/j.1365-2745.2011.01941.x

Migliavacca M, Galvagno M, Cremonese E, Rossini $M$, Meroni $M$, Sonnentag $O$, Cogliati $S$, Manca G, Diotri F, Busetto L, Cescatti A, Colombo R, Fava F, Celia UM, Pari E, Siniscalco C, Richardson AD (2011). Using digital repeat photography and eddy covariance data to model grassland phenology and photosynthetic $\mathrm{CO}_{2}$ uptake. Agricultural and Forest Meteorology 151: 1325-1337. - doi: 10.1016/j.agrformet.2011.05. 012

Myneni RB, Keeling CD, Tucker CJ, Asrar G, Nemani RR (1997). Increased plant growth in the northern high latitudes from 1981 to 1991. Nature 386: 698-702. - doi: 10.1038/386698ao

Neeman G (1993). Variation in leaf phenology and habit in Quercus ithaburensis, a Mediterranean deciduous tree. Journal of Ecology 81: 627-634. - doi: 10.2307/2261661

Partanen J, Koski V, Hanninen H (1998). Effects of photoperiod and temperature on the timing of bud burst in Norway spruce (Picea abies). Tree Physiology 18: 811-816. - doi: 10.1093/tree phys/18.12.811

Pauley SS, Perry TO (1954). Ecotypic variation of the photoperiodic response in Populus. Journal of the Arnold Arboretum 35: 167-188.

Pellis A, Laureysens I, Ceulemans R (2004a). Genetic variation of the bud and leaf phenology of seventeen poplar clones in a short rota- tion coppice culture. Plant Biology 6: 1-9. - doi: 10.1055/s-2004-815737

Pellis A, Laureysens I, Ceulemans R (2004b). Growth and production of a short rotation coppice culture of poplar I. Clonal differences in leaf characteristics in relation to biomass production. Biomass and Bioenergy 27: 9-19. - doi: 10.1016/j.biombioe.2003.11.001

R core team (2013). R: a language and environment for statistical computing. $R$ foundation for statistical computing, Vienna, Austria.

Richardson AD, Braswell BH, Hollinger DY, Jenkins JP, Ollinger SV (2009a). Near-surface remote sensing of spatial and temporal variation in canopy phenology. Ecological Applications 19: 1417-1428. - doi: 10.1890/08-2022.1

Richardson AD, Hollinger DY, Dail DB, Lee JT, Munger JW, Keefe J (2009b). Influence of spring phenology on seasonal and annual carbon balance in two contrasting New England forests. Tree Physiology 29: 321-331. - doi: 10.1093/treephys/tpno40

Richardson AD, Jenkins JP, Braswell BH, Hollinger DY, Ollinger SV, Smith ML (2007). Use of digital webcam images to track spring green-up in a deciduous broadleaf forest. Oecologia 152: 323-334. - doi: 10.1007/s00442-006-0657-z

Richardson AD, Keenan TF, Migliavacca M, Ryu Y, Sonnentag O, Toomey M (2013). Climate change, phenology, and phenological control of vegetation feedbacks to the climate system. Agricultural and Forest Meteorology 169: 156173. - doi: 10.1016/j.agrformet.2012.09.012

Rohde A, Bastien C, Boerjan W (2011a). Temperature signals contribute to the timing of photoperiodic growth cessation and bud set in poplar. Tree Physiology 31: 472-482. - doi: 10.1093/ treephys/tpro38

Rohde A, Storme V, Jorge V, Gaudet M, Vitacolonna N, Fabbrini F, Ruttink T, Zaina G, Marron $N$, Dillen SY, Steenackers $M$, Sabatti $M$, Morgante M, Boerjan W, Bastien C (2011b). Bud set in poplar - genetic dissection of a complex trait in natural and hybrid populations. New Phytologist 189: 106-121. - doi: 10.1111/j.1469-81 37.2010.03469.x

Root TL, Price JT, Hall KR, Schneider SH, Rosenzweig C, Pounds JA (2003). Fingerprints of global warming on wild animals and plants. Nature 421: 57-60. - doi: 10.1038/nature01333

Rouse JW, Haas RH, Schell JA, Deering DW (1974). Monitoring vegetation systems in the Great Plains with Erts. In: Proceedings of the " 3 "rd Earth Resources Technology Satellite-1 Symposium- Volume I: Technical Presentations" (Freden SC, Mercanti EP, Becker MA eds). Goddard Space Flight Center (Washington, DC, USA) 10-14 Dec 1973. NASA SP-351, Washington, DC, USA, pp. 309-317. [online] URL: http:// adsabs.harvard.edu/abs/1974NASSP.351..309R

Sainte-Marie J, Saint-Andre L, Nouvellon Y, Laclau JP, Roupsard O, Le Maire G, Delpierre N, Henrot A, Barrandon M (2014). A new probabilistic canopy dynamics model (SLCD) that is suitable for evergreen and deciduous forest ecosystems. Ecological Modelling 290: 121-133. doi: 10.1016/j.ecolmodel.2014.01.026

Schwartz MD (2013). Phenology: an integrative environmental science. SpringerLink, Dordrecht, the Netherlands, pp. 610.

Seiwa K (1998). Advantages of early germination for growth and survival of seedlings of Acer mono under different overstorey phenologies in deciduous broad-leaved forests. Journal of Ecology 86: 219-228. - doi: 10.1046/j.1365-2745. 1998.00245.x

Sonnentag O, Hufkens K, Teshera-Sterne C, Young AM, Friedl M, Braswell BH, Milliman T, O'Keefe J, Richardson AD (2012). Digital repeat photography for phenological research in forest ecosystems. Agricultural and Forest Meteorology 152: 159-177. - doi: 10.1016/j.agrformet.20 11.09.009

Soudani K, Hmimina G, Delpierre N, Pontailler JY, Aubinet $\mathrm{M}$, Bonal $\mathrm{D}$, Caquet $\mathrm{B}$, De Grandcourt A, Burban B, Flechard C, Guyon D, Granier A, Gross $\mathrm{P}$, Heinesh B, Longdoz B, Loustau D, Moureaux C, Ourcival JM, Rambal S, Saint Andre L, Dufrene E (2012). Ground-based network of NDVI measurements for tracking temporal dynamics of canopy structure and vegetation phenology in different biomes. Remote Sensing of Environment 123: 234-245. - doi: 10.1016/j. rse.2012.03.012

Soudani K, Le Maire G, Dufrene E, Francois C, Delpierre N, Ulrich E, Cecchini S (2008). Evaluation of the onset of green-up in temperate deciduous broadleaf forests derived from Moderate Resolution Imaging Spectroradiometer (MODIS) data. Remote Sensing of Environment 112: 2643-2655. - doi: 10.1016/j.rse.2007.12.004 Sparks TH, Carey PD (1995). The responses of species to climate over 2 centuries - an analysis of the Marsham phenological record, 17361947. Journal of Ecology 83: 321-329. - doi: $10.2307 / 2261570$

Tan B, Woodcock CE, Hu J, Zhang P, Ozdogan M, Huang D, Yang W, Knyazikhin Y, Myneni RB (2006). The impact of gridding artifacts on the local spatial properties of MODIS data: implications for validation, compositing, and band-toband registration across resolutions. Remote Sensing of Environment 105: 98-114. - doi: 10.1016/j.rse.2006.06.008

Turok J, Lefèvre F, Cagelli L, De Vries S (1996). Populus nigra network. Report of the second meeting, Casale Monferrato (Italy) 10-12 Sep 1995. International Plant Genetic Resources Institute, Rome, Italy, pp. 26. [online] URL: http://library.wur.nl/WebQuery/wurpubs/report s/303240

Verlinden MS, Broeckx LS, Ceulemans R (2015). First vs. second rotation of a poplar short rotation coppice: above-ground biomass productivity and shoot dynamics. Biomass and Bioenergy 73: 174-185. - doi: 10.1016/j.biombioe.2014.12.012 Verlinden MS, Broeckx LS, Van Den Bulcke J, Van Acker J, Ceulemans R (2013). Comparative study of biomass determinants of 12 poplar ( $P$ pulus) genotypes in a high-density short-rotation culture. Forest Ecology and Management 307: 101-111. - doi: 10.1016/j.foreco.2013.06.062

Viña A, Gitelson AA (2005). New developments in the remote estimation of the fraction of absorbed photosynthetically active radiation in crops. Geophysical Research Letters 32: L17403. - doi: 10.1029/2005GL023647

Viña A, Henebry GM, Gitelson AA (2004). Satellite monitoring of vegetation dynamics: sensitivity enhancement by the wide dynamic range vegetation index. Geophysical Research Letters 31: L04503. - doi: 10.1029/2003GL019034 
Vitasse Y, Lenz A, Hoch G, Korner C (2014). Earlier leaf-out rather than difference in freezing resistance puts juvenile trees at greater risk of damage than adult trees. Journal of Ecology 102: 981-988. - doi: 10.1111/1365-2745.12251

Wu CY, Gonsamo A, Gough CM, Chen JM, Xu SC (2014). Modeling growing season phenology in North American forests using seasonal mean vegetation indices from MODIS. Remote Sensing of Environment 147: 79-88. - doi: 10.1016/ j.rse.2014.03.001

Zhang XY, Friedl MA, Schaaf CB, Strahler AH, Hodges JCF, Gao F, Reed BC, Huete A (2003). Monitoring vegetation phenology using MODIS. Remote Sensing of Environment 84: 471-475. - doi: 10.1016/So034-4257(02)00135-9
Zona D, Janssens IA, Aubinet M, Gioli B, Vicca S, Fichot R, Ceulemans R (2013). Fluxes of the greenhouse gases $\left(\mathrm{CO}_{2}, \mathrm{CH}_{4}\right.$ and $\left.\mathrm{N}_{2} \mathrm{O}\right)$ above a short-rotation poplar plantation after conversion from agricultural land. Agricultural and Forest Meteorology 169: 100-110. - doi: 10.1016/ j.agrformet.2012.10.008 